\title{
Risk Assessment of Repetitive Tasks: A Comparative Analysis among Different Methods to Update the Maximum Frequency Allowed
}

\author{
Guido Alfaro Degan ${ }^{1}$, Andrea Antonucci ${ }^{2 *}$, Gianluca Coltrinari ${ }^{1}$, Dario Lippiello ${ }^{1}$ \\ ${ }^{1}$ University of Rome - Roma TRE, 00146, Italy \\ ${ }^{2}$ University of Chieti - G. d'Annunzio, 66100, Italy
}

Corresponding Author Email: andrea.antonucci@unich.it

https://doi.org/10.18280/ijsse.100114

Received: 19 July 2019

Accepted: 5 September 2019

\section{Keywords:}

revised strain index, OCRA index, ACGIH, strain index, risk assessment, upper extremity disorders, frequency of movements, repeated movements

\begin{abstract}
A comparison in terms of the maximum frequency of movement allowed in the no-risk area, when varying the force and the duty cycle, was made among the follows methods: Strain Index (SI), Revised Strain Index (RSI), Occupational Repetitive Action (OCRA) Index and ACGIH (TLV). The RSI provides similar results to the OCRA Index and ACGIH(TLV) in less than $1 / 3$ of the overall pre-set combinations of force (BS) and duty cycle (DC). Some of the highlights are as follows: the ACGIH (TLV) method allows 6 exertions per second in the net time of the cycle, while the RSI less than 1, in the hypothesis of BS=1 and DC $=60 \%$; in the same conditions, but for a DC $=100 \%$, the ACGIH(TLV) allows almost 2 exertions per second while the RSI and the OCRA Index do not consider any frequency of movement as "safe" in this circumstance; in the same conditions but when $\mathrm{DC}=20 \%$ and $\mathrm{BS}=5$, the RSI method allows less than 0.5 exertions per second, while using the OCRA Index it is possible to stay in the "safe" area even if the exertions per second are over 4. More epidemiological data would be desirable to better define the boundary conditions used by the methods.
\end{abstract}

\section{INTRODUCTION}

Jobs requiring a combination of high force and high repetition of movements are indicated as the most responsible in developing distal upper extremity (DUE) work-related musculoskeletal disorders (WMSDs) [1-3]. Conditions in which workers are forced to operate by making repeated movements in addition to using high force are common in several task jobs, such as in assembly lines and construction sectors [4-8]. Other factors, like the duration of repeated movements and awkward postures, along with the existence of complementary physical, psychological and environmental factors, can also contribute to developing WMSDs [9-11].

The standard ISO 11228-3:2007 [12] indicates the Occupational Repetitive Action (OCRA) Index [13] as one of the preferred methods for an analytical evaluation of WMSDs, but other methods are also frequently used in the field, such as the American Conference of Governmental Industrial Hygienists Threshold Limit Values ACGIH (TLV) [14] and the Strain Index (SI) [15].

These assessment methods use different calculation algorithms, which consider a number of different variables to determine the risk, and for this reason the results are sometimes conflicting [16-21].

In a previous study (Antonucci [22]) an analysis of the algorithms of the previous methods for the assessment of DUE-WMSDs was made in order to highlight the differences in terms of number of parameters considered in the formulas, range of variability for each one, and their interaction in determining the final results.

Recently, a new algorithm of the SI, the Revised Strain Index (RSI) [23], was presented, introducing some important modifications. Among these, one of the most important is the use of continuous rather than categorical multipliers. This improvement results in a more sensitive variation of the multipliers inside the formula, allowing to solve the problem of having, in some cases, a jump in terms of results, even in the case of a little variation of the parameters evaluated.

Moreover, the new algorithm allows one to obtain different results associated with the increase of the number of hours worked, when they vary from 4 to 8 . The new algorithm also solves the problem of having a fixed multiplier for tasks involving 20 or more exertions per minute, in addition to the possibility to better differentiate the duty cycle having different durations of exertions.

Based on the previous study [22], in which the frequency (efforts/second) allowed in the no-risk area for each of the examined methods when varying the force and the duty cycle was analyzed among other things, in the present study the same methodology was applied in order to estimate some modifications in the use of the RSI compared to its 1995 version $(\mathrm{SI})$.

\section{METHODOLOGY}

This study analyzes the maximum frequency of movement allowed in the no-risk area at different levels of duty cycle (DC) and applied force for the following methods used for the assessment of DUE-WMSDs: SI, ACGIH(TLV), OCRA Index and RSI.

Regarding the SI, a safe threshold limit set at 6 was also used to determine the maximum frequency of movement, since the method identifies an area of uncertain risk ranging from 3 to 6 [24].

In the following section, a summary of the hypotheses made 
and some of the calculations from the previous study [22] are briefly reported in order to have an idea of the origin of some of the data used in the discussion.

\subsection{Hypotheses made for the calculation of the frequency for ACGHI(TLV) and Ocra Index}

In order to calculate the maximum frequency of movement (number of efforts per second in the net time of the cycle) that each method allows, in no-risk conditions varying the force and the duty cycle, a very easy task was considered involving only one postural variable such as the ulnar deviation of the wrist, e.g. when using a joystick lever. Both the push forward movements and the return to neutral position movements can be considered active i.e. employing force.

We started considering the method with the lowest number of variables in the evaluation algorithm, in order to fix the same working conditions for the other methods. In our case it is the ACGIH(TLV). The equation determining the action limit of risk (calculated from the two extreme values indicated in the ACGIH(TLV) graphic is as follows:

$$
N P F_{A L}=5.56-0.556 * H A L
$$

in which $N P F_{A L}$ is the Normalized Peak Force, which in our case, for a better comparison of the methods, was made to coincide with the force value provided on the Borg Scale (from now on indicated by BS) [25].

To calculate the frequency the following formula was used:

$$
f=\left(\frac{H A L}{6.56 \ln D C-3.18 H A L}\right)^{\frac{1}{1.31}}
$$

in which $D C$ is the duty cycle and $f$ is the frequency of movement (the number of work movements per second considered in the net time of the cycle), derived from the formula proposed by Radwin et al. [26] for the calculation of HAL. From Eq. (1) the border line conditions (action limit) were obtained when varying the force. These are the following conditions: $\mathrm{BS}=1, \mathrm{HAL}=8.20 ; \mathrm{BS}=2, \mathrm{HAL}=6.40 ; \mathrm{BS}=3$, $\mathrm{HAL}=4.60, \mathrm{BS}=4, \mathrm{HAL}=2.81 ; \mathrm{BS}=5, \mathrm{HAL}=1.01$.

The values calculated for HAL were then inserted in Eq. (2) and different DC values were hypothesized (100\%, 80\%, 60\%, $40 \%$, and $20 \%$ ) to find the values of frequency allowed for the no-risk area. These are reported in Table 1, assuming a 1minute cycle time.

The SI method considers more parameters of evaluation compared to the ACGIH(TLV), so other conditions were set, and the same goes for the previous hypotheses without altering the results already obtained. Since the ACGIH(TLV) leaves to the expert assessor the possibility to modify the final result in case of awkward posture, and this was not done, a non-harmful posture was hypothesized. Regarding the rhythm (speed) of work $(R)$, although it also depends on the frequency, it was possible to assign, in all the different hypotheses made, the coefficient $R=1$, since the frequency allowed for the no-risk conditions that derives from our calculations never exceeded 1.7 movements per second, which can be considered a "fair" work rhythm. The duration of a repetitive task is assumed to be between 4 and 8 hours. Applying the following formula, the parameter $F$ was calculated:

$$
I * D * F * P * R * T=3 \text { or } 6
$$

In Eq. (3) the variables are those used by the SI method: $I=$ intensity of exertion; $D=$ duration of exertion; $F=$ Efforts/minute; $P=$ posture; $R=$ speed of work; $T=$ duration per day, considering, on the basis of the previous hypotheses, $P=R=T=1$.

Parameter $F$ in Eq. (3) derives from the number of exertions in one minute $\left(F^{\prime}\right)$ according to the following correlation identified by the SI method: $F=0.5$ if $F^{\prime}<4 ; F=1$ if $4<F^{\prime}<8$; $F=1.5$ if $9<F^{\prime}<14 ; F=2$ if $15<F^{\prime}<19 ; F=3$ if $F^{\prime} \geq 20$.

It is important to note that, even though $F$, represents "frequency of movements", it must not be confused with the frequency $f$ in Eq. (2). In fact, $F$ ' refers to the average exertions calculated in a time-period of one minute starting from the number of exertions in the cycle time. This calculation also includes any breaks in work within the cycle (work time + rest time within the cycle). The frequency $f$ considered in Eq. (2) refers to the number of exertions per second within the nettime of the cycle. For a comparison of the frequencies $f$ and $F$, the following correlation must be considered, valid for the hypothesis made in a 1-minute cycle time.

$$
f=\frac{\frac{F^{\prime}}{\frac{60}{D C}}}{\frac{100}{60 * D C}}
$$

Since we are looking for the maximum frequency allowed in the no-risk area, we chose the highest value of $F^{\prime}$ for each corresponding $F$.

Regarding the values to assign to the OCRA Index algorithm, the previously set working conditions were maintained, but further specifications were made, since the method requires a greater definition of the parameters inserted in the algorithm. A hypothesis of non-existence of complementary factors was made in order to avoid influencing the results already obtained using the other methods. The following conditions remain valid for the previous results as well since the working time is fixed, so far, varying from 4 to 8 hours:

hypothesis (A): 4 hours of repeated work arranged as follows: 2 consecutive hours in the morning and 2 consecutive hours in the afternoon, with a 1 - hour lunch break, and the remaining time in non-repetitive work;

- $\quad$ hypothesis (B): 6 hours of repeated work arranged as follows: 3 consecutive hours in the morning and 3 consecutive hours in the afternoon, with a 1-hour lunch break, and the remaining time in non-repetitive work;

- $\quad$ hypothesis (C): 8 hours of repeated work arranged as follows: 4 consecutive hours in the morning and 4 consecutive hours in the afternoon, with a 1-hour lunch break.

From the OCRA Index formula (mono-task job), in the respect of our hypotheses, the following relation is derived in the border line conditions of no-risk:

$$
\frac{A T A}{R T A}=\frac{F * T}{30 * a * b * c * d * T * e * g}=2
$$

in which $a=\mathrm{F}_{\mathrm{om}}$ (force multiplier), $b=\mathrm{P}_{\text {om }}$ (posture multiplier), $c=\mathrm{R}_{\mathrm{em}}$ (stereotype multiplier), $d=\mathrm{A}_{\mathrm{dm}}$ (complementary factors multiplier), $e=\mathrm{R}_{\mathrm{cm}}$ (recovery time multiplier), and $g=\mathrm{D}_{\mathrm{um}}$ 
(duration multiplier). Parameter F in the formula of the OCRA Index method represents the average number of technical actions (in our hypotheses coinciding with a single effort or movement) per minute in a complete cycle, including the breaks, therefore, in agreement with what was previously considered for the SI method, correlation (4) in Eq. (5) was used from which, by simplifying, the following formula for the calculation of frequency is obtained:

$$
f=\frac{110 * a * b * c * d * T * e * g}{T * D C}
$$

in which $f=$ number of technical actions per second allowed as maximum frequency in the no-risk range in the set conditions.

For the details regarding the definition of each multiplier in Eq. (6) refer to the following publication (Antonucci [22]).

\subsection{Hypotheses made for the calculation of the frequency for the RSI method}

To be consistent with the data coming from the previous study, the same previous hypotheses were conserved in this case as well.

Regarding the RSI algorithm, since 10 is the borderline value for the no risk area, the formula for the calculation of the maximum frequency of movements in the no risk area is as follows:

$$
R S I=I M \cdot E M \cdot D M \cdot P M \cdot H M=10
$$

in which the multipliers are those indicated by the method: $I M=$ intensity of exertion (force); $E M=$ exertion per minute (frequency); $D M=$ duration per exertion; $P M=$ hand/wrist posture; $H M=$ duration of task per day.

The RSI method provides two formulas for the calculation of the HM multiplier related to the number of hours worked. In our hypotheses, since the number of hours worked was set from 4 to 8 , the following formula was used:

$$
H M=0.042 \cdot H+0.09 \cdot \log _{e}(H)+0.477
$$

where, $\mathrm{H}$ is the number of hours worked in a day. Also in this case 3 different scenarios are supposed, similar to what was previously set for the OCRA Index algorithm. In this case HM assumes the following values: $H M=0.77$ (for 4 hours); $H M=0.89$ (for 6 hours); $H M=1$ (for 8 hours).

Regarding the Intensity of exertion multiplier (IM), as done before, instead of using the percentage of maximum strength (\%MVC), we use the Borg CR-10 perceived exertion scale (BS) [25]. In this case, as reported by the RSI method [23] for BS equal or lower than 4 , we use the following formula:

$$
I M=30 \cdot I^{3}-15.6 \cdot I^{2}+13 \cdot I+0.4
$$

and for BS over than 4:

$$
I M=36 \cdot I^{3}-33.3 \cdot I^{2}+24.77 \cdot I-1.86
$$

in which $I$ varies from 0 to 1 according to the variation of BS from 0 to 10 .

The results are the following: $\mathrm{IM}=25.61$ (for $\mathrm{BS}=10$ ); $\mathrm{IM}=15.08$ (for $\mathrm{BS}=8$ ); $\mathrm{IM}=8.79$ (for $\mathrm{BS}=6$ ); $\mathrm{IM}=6.70$ (for $\mathrm{BS}=5$ ); $\mathrm{IM}=5.02$ (for $\mathrm{BS}=4$ ); $\mathrm{IM}=3.71$ (for $\mathrm{BS}=3$ ); $\mathrm{IM}=2.62$ (for $\mathrm{BS}=2$ ); $\mathrm{IM}=1.57$ (for $\mathrm{BS}=1$ )

Regarding the hand/wrist posture multiplier (PM), a nonharmful posture was hypothesized in this case as well. In this hypothesis, the PM multiplier can be fixed as 1 .

Regarding the calculation of the duration per exertion multiplier (DM), since we hypothesized a 1-minute cycle time, the following formula is used:

$$
D M=0.45+0.31 \cdot D
$$

in which $\mathrm{D}$ is the duration per exertion measured in seconds. The parameter $\mathrm{D}$ is calculated by dividing the total exertion time (in seconds) by the number of exertions done in the same time, in other words, it is the reciprocal of the frequency (f) that we are looking for. Therefore, to calculate DM the following formula can be used:

$$
D M=0.45+0.31 \cdot\left(\frac{1}{f}\right)
$$

in which $\mathrm{f}$ is the number of exertions per second referring to the net time of the cycle.

The efforts per minute multiplier (EM) depends on parameter E (efforts per minute) which is calculated by dividing the number of efforts in a cycle by the duration of the cycle (in minutes). This parameter $\mathrm{E}$, can also refer to the frequency (f) that we are looking for. In fact, having hypothesized in our case a 1-minute cycle time, and assuming there is no rest time from one cycle to another except for the time within the cycle, in which there are no efforts determined by the duty cycle (DC), we can express E in terms of DC and $f$ as the following formula:

$$
E=\frac{f \cdot 60 \cdot D C}{100}
$$

in which as specified before:

$$
\begin{gathered}
f=\left(\frac{\text { number of exertions }}{\text { work time in the cycle }(\text { in seconds })}\right) \\
D C=100 \cdot\left(\frac{\text { work time in the cycle }}{\text { total time of the cycle }}\right)
\end{gathered}
$$

Since the RSI method uses two different formulas for the calculation of the EM multiplier which depends on the number of efforts per minute, in the first step of our calculation both formulas are used. Then, looking at the results, the right one was chosen based on the value of frequency $f$.

As an example of the calculations done, in the hypothesis of a total work time of 4 hours a day, $\mathrm{DC}=60 \%$ and force $(\mathrm{BS})=$ 2 , the formulas for the calculation of the maximum frequency of movements in the no risk area for the RSI are as follows:

$$
\begin{aligned}
2.62 \cdot(0.1+0.25 & \left.\cdot\left(\frac{f \cdot 60 \cdot 60}{100}\right)\right) \cdot\left(0.45+0.31 \cdot\left(\frac{1}{f}\right)\right) \\
\cdot 1 \cdot 0.77=10 & \\
2.62 \cdot( & \left.0.00334 \cdot\left(\frac{f \cdot 60 \cdot 60}{100}\right)^{1.96}\right) \\
& \left(0.45+0.31 \cdot\left(\frac{1}{f}\right)\right) \cdot 1 \cdot 0.77=10
\end{aligned}
$$


We choose the value of $f$ deriving from Eq. (14) or Eq. (15) according to the value of $E$ obtained using Eq. (13). If $E$ is below or equal to 90 (efforts/min) the correct $\mathrm{f}$ value $\mathrm{r}$ is the one deriving from Eq. (14), otherwise, if $\mathrm{E}$ is over 90 (efforts/min), the correct $\mathrm{f}$ value will derive from Eq. (15).

\section{RESULTS AND DISCUSSION}

As expected, the results in table 1 show that the RSI is more accurate than the SI in determining the different frequency of movement allowed in the no-risk area when varying the set parameters. In fact, using the SI formula, the maximum frequency calculated is the same for both forces $\mathrm{BS}=1$ and $\mathrm{BS}=2$ as for $\mathrm{BS}=4$ and $\mathrm{BS}=5$ in each set Duty Cycle. Moreover, the RSI is also more accurate in determining the different frequency of movement allowed in the no-risk area when varying the number of hours worked, while the SI fixes the same frequency without any distinction from 4 to 8 hours of work per day.

These remarkable differences are due to the fact that the new algorithm for the RSI uses continuous rather than categorical multipliers, so it is always possible to have a variation of results when varying the condition of work related to frequency, force, posture, and total time worked.

The table of results shows that the RSI, and the SI, are the most precautionary methods among those examined. Both the RSI and SI in fact, allow a lower number of efforts per second in the no-risk area than the other methods for almost all combinations of DC and force, in the hypothesis made of a good posture and assuming a 1-minute cycle time. The only exception is when $\mathrm{DC}=20 \%$ and the force is over $\mathrm{BS}=3$, where the ACGIH(TLV) method is more precautionary.

When the $\mathrm{DC}=100 \%$, while it is not possible to have results in the no-risk area when using the SI algorithm (even with a very low force and in the hypothesis of a good posture), the RSI admits some frequency of effort, but only in the case of a very low force $(B S=1)$. These frequencies of movement are also similar to the frequencies allowed by the OCRA Index method in the same working conditions. The ACGIH method, on the contrary, admits a frequency of movement 7 times more than the other methods in the same conditions of DC and force applied when the number of hours worked is 8 , always assuming good posture.

The reason for this result is the fact that in the SI formula the multiplier related to "Efforts per minute" has to be set to 3 when the duration of exertion (DC) is $100 \%$. In this condition, it is impossible to have a result inside the no-risk area, even with a very low force and a good posture. In the RSI formula, in the hypotheses made, the product of the EM and DM multipliers never has a result lower than 5 , and so the only frequency of movement admitted in the no-risk area when $\mathrm{DC}=100 \%$ is when the force never exceeds $\mathrm{BS}=1$.

In the ACGIH(TLV) algorithm the force is taken into great consideration (about $73 \%$ of the risk determination) [22], this is the reason that the number of exertions allowed in the norisk area decreases markedly as the applied force increases, far more than the other assessment methods examined and irrespective of the DC considered.

In order to have a better comprehension of the results, in addition to evaluating them in a similar way to what could be observed in a real field case study, some simplifications can be made, such as considering all frequencies of movement that differ by less than 0.3 efforts per second as identical, and considering the frequencies of less than 0.3 efforts per second (no frequency of movement allowed) as a static position.

Assuming the above hypotheses, all the frequencies of movement admitted in the no-risk area and calculated using the SI formula are never greater than those calculated using the RSI, when the safe threshold limit is set at 3 (indicated by $\mathrm{SI}(3)$ ), and this is regardless of the number of hours worked. More specifically, in $65 \%$ of the cases resulting from the combination of force and DC, the frequencies allowed in the no-risk area can be considered approximately the same for both methods; in the remaining 35\%, generally for DC less than $60 \%$, the RSI admits more efforts per second, even more than triple in some particular combinations of DC and force applied. The results are shown in Table 2.

When the safe threshold limit is set at 6 (indicated by SI(6)), the SI(6) and the RSI show similar results in about $66 \%$ of the combinations of force and DC analyzed, while in almost $29 \%$ the efforts per second admitted by the RSI are lower than those admitted by the SI(6). In only 5\% of the cases the RSI allows more efforts per second than the SI(6), and among those, the number of hours worked is never greater than or equal to 6 .

Comparing the results in terms of frequency for both the RSI and the OCRA Index, the number of efforts per second allowed in the no-risk area is greater for the OCRA Index in about $80 \%$ of the set combinations of force and DC; in the remaining $20 \%$, the results can be considered similar. In no case does the RSI admit more efforts per second compared to the OCRA Index, regardless of the number of hours worked.

In the same conditions, comparing the results of the SI(6) with those provided by OCRA Index, in $67 \%$ of the cases the $\mathrm{SI}(6)$ is more precautionary compared to OCRA, admitting less exertions per second, while in about $27 \%$ of the cases the results can be considered equal, and in only $6 \%$ of the combinations of force and DC the SI(6) allows a frequency of movement in the no-risk area greater than the OCRA Index.

Looking at the results when the safe threshold limit is set at 3 , in $85 \%$ of the cases the frequency of effort is greater in the OCRA Index than in the SI(3), in the remaining $15 \%$ the results can be considered similar, in no case does the SI(3) admit a frequency of movement greater than the OCRA Index.

The ACGIH(TLV) method provides similar results to the RSI in about $35 \%$ of the cases, while the frequency allowed in the no-risk area is greater for the ACGIH(TLV) in 53\% of the combinations of DC and force, while in about $12 \%$ the opposite happens.

Table 2 also shows that the SI(6) and the RSI have a greater match $(66 \%)$ in terms of the maximum frequency admitted in the no-risk area, (for the different combinations of DC and force investigated), compared to the other methods. Regarding the comparison with the OCRA Index method, even though the RSI admits the possibility to vary the number of hours worked, the results show more agreement in terms of frequency allowed in the no-risk area between SI(6) and OCRA Index $(27 \%)$ than between RSI and OCRA Index (20\%), showing also that the OCRA Index admits a frequency of movement generally higher than the other two algorithms. In general, it can be seen that the RSI, as well as the SI(3) and SI(6), are more precautionary in terms of frequency of movement compared to the other methods. 
Table 1. Maximum number of exertions per second allowed in the no-risk area varying the force and the duty cycle Hypothesis of 1-minute cycle time

\begin{tabular}{|c|c|c|c|c|c|c|c|c|c|c|}
\hline & & $\begin{array}{c}\text { ACGIH } \\
\text { (TLV) }\end{array}$ & SI (3) & SI (6) & $\begin{array}{c}\text { RSI } \\
4 \text { hours }\end{array}$ & $\begin{array}{c}\text { RSI } \\
6 \text { hours }\end{array}$ & $\begin{array}{c}\text { RSI } \\
8 \\
\text { hours }\end{array}$ & $\begin{array}{l}\text { OCRA } \\
\text { Index } \\
4 \text { hours }\end{array}$ & $\begin{array}{l}\text { OCRA } \\
\text { Index } \\
6 \text { hours }\end{array}$ & $\begin{array}{c}\text { OCRA } \\
\text { Index } \\
8 \text { hours } \\
\end{array}$ \\
\hline $\begin{array}{c}\text { Force } \\
\text { Borg scale }\end{array}$ & $\begin{array}{c}\text { Duty } \\
\text { Cycle (\%) }\end{array}$ & $\begin{array}{c}\mathrm{f} \\
\text { Exert./s }\end{array}$ & $\begin{array}{c}\mathrm{f} \\
\text { Exert./s }\end{array}$ & $\begin{array}{c}\mathrm{f} \\
\text { Exert./s }\end{array}$ & $\begin{array}{c}\mathrm{f} \\
\text { Exert./s }\end{array}$ & $\begin{array}{c}\mathrm{f} \\
\text { Exert./s }\end{array}$ & $\begin{array}{c}\mathrm{f} \\
\text { Exert./s }\end{array}$ & $\begin{array}{c}\mathrm{f} \\
\text { Exert./s }\end{array}$ & $\begin{array}{c}\mathrm{f} \\
\text { Exert./s }\end{array}$ & $\begin{array}{c}\mathrm{f} \\
\text { Exert./s }\end{array}$ \\
\hline 1 & 100 & 1.69 & $*$ & $*$ & 0.52 & 0.35 & 0.23 & 0.79 & 0.47 & 0.16 \\
\hline 2 & 100 & 0.72 & $*$ & $*$ & $*$ & $*$ & $*$ & 0.60 & 0.36 & 0.13 \\
\hline 3 & 100 & 0.39 & $*$ & $*$ & $*$ & $*$ & $*$ & 0.32 & 0.19 & 0.07 \\
\hline 4 & 100 & 0.21 & $*$ & $*$ & $*$ & $*$ & $*$ & 0.18 & 0.11 & 0.04 \\
\hline 5 & 100 & 0.08 & $*$ & $*$ & $*$ & $*$ & $*$ & $*$ & $*$ & $*$ \\
\hline 1 & 80 & 2.35 & 0.17 & 0.39 & 0.83 & 0.62 & 0.47 & 1.32 & 1.05 & 0.88 \\
\hline 2 & 80 & 0.81 & 0.17 & 0.39 & 0.19 & $*$ & $*$ & 1.06 & 0.85 & 0.71 \\
\hline 3 & 80 & 0.42 & $*$ & 0.08 & $*$ & $*$ & $*$ & 0.77 & 0.61 & 0.51 \\
\hline 4 & 80 & 0.23 & $*$ & $*$ & $*$ & $*$ & $*$ & 0.46 & 0.37 & 0.31 \\
\hline 5 & 80 & 0.08 & $*$ & $*$ & $*$ & $*$ & $*$ & 0.29 & 0.23 & 0.19 \\
\hline 1 & 60 & 6.01 & 0.39 & $2>0.55$ & 1.34 & 1.06 & 0.86 & 1.86 & 1.49 & 1.24 \\
\hline 2 & 60 & 0.99 & 0.39 & $2>0.55$ & 0.51 & 0.34 & 0.2 & 1.56 & 1.25 & 1.04 \\
\hline 3 & 60 & 0.47 & 0.11 & 0.22 & $*$ & $*$ & $*$ & 1.33 & 1.06 & 0.88 \\
\hline 4 & 60 & 0.24 & $*$ & 0.11 & $*$ & $*$ & $*$ & 1.02 & 0.81 & 0.68 \\
\hline 5 & 60 & 0.09 & $*$ & 0.11 & $*$ & $*$ & $*$ & 0.67 & 0.54 & 0.45 \\
\hline 1 & 40 & $>10$ & 0.79 & $2>0.83$ & 2.35 & 1.94 & 1.65 & 4.13 & 3.30 & 2.75 \\
\hline 2 & 40 & 1.47 & 0.79 & $2>0.83$ & 1.12 & 0.87 & 0.69 & 3.75 & 3.00 & 2.50 \\
\hline 3 & 40 & 0.57 & 0.16 & 0.33 & 0.57 & 0.37 & 0.25 & 3.34 & 2.67 & 2.23 \\
\hline 4 & 40 & 0.27 & $*$ & 0.16 & 0.19 & $*$ & $*$ & 3.01 & 2.41 & 2.01 \\
\hline 5 & 40 & 0.10 & $*$ & 0.16 & $*$ & $*$ & $*$ & 2.68 & 2.15 & 1.79 \\
\hline 1 & 20 & $>10$ & $\begin{array}{c}2 \\
>1.67\end{array}$ & $\begin{array}{c}\text { no } \\
\text { limit }>1.6 \\
7\end{array}$ & 5.40 & 4.57 & 3.99 & 8.25 & 6.60 & 5.50 \\
\hline 2 & 20 & $>10$ & $\begin{array}{c}2 \\
>1.67 \\
\end{array}$ & $\begin{array}{c}\text { no limit } \\
>1.67\end{array}$ & 2.94 & 2.45 & 2.09 & 8.25 & 6.60 & 5.50 \\
\hline 3 & 20 & 0.93 & 0.67 & 1.58 & 1.86 & 1.51 & 1.26 & 8.00 & 6.40 & 5.34 \\
\hline 4 & 20 & 0.36 & 0.33 & 0.66 & 1.17 & 0.91 & 0.72 & 7.51 & 6.01 & 5.01 \\
\hline 5 & 20 & 0.12 & 0.33 & 0.66 & 0.68 & 0.47 & 0.31 & 7.01 & 5.61 & 4.68 \\
\hline
\end{tabular}

Table 2. Percentage of agreement in terms of efforts/sec

\begin{tabular}{|c|c|c|c|}
\hline & $\begin{array}{c}a)=b) \\
(\%)\end{array}$ & $\begin{array}{c}\text { a) }>\text { b) } \\
(\%)\end{array}$ & $\begin{array}{c}\text { b) }>\text { a) } \\
(\%)\end{array}$ \\
\hline a) ACGIH b) SI (3) & 36 & 60 & 4 \\
\hline a) ACGIH b) SI (6) & 48 & 36 & 16 \\
\hline a) ACGIH b) RSI & 35 & 53 & 12 \\
\hline a) ACGIH b) OCRA & 24 & 29 & 47 \\
\hline a) SI (3) b) RSI & 65 & 0 & 35 \\
\hline a) SI (3) b) OCRA & 15 & 0 & 85 \\
\hline a) SI (3) & 60 & 0 & 40 \\
\hline a) SI (6) & 66 & 29 & 5 \\
\hline a) SI (6) b) OCRA & 27 & 6 & 67 \\
\hline b) OCRA & 20 & 0 & 80 \\
\hline
\end{tabular}

\section{CONCLUSIONS}

This paper analyzed the maximum frequency allowed in the no-risk area at different levels of force and DC for some of the most used methods for the evaluation of DUE symptoms and/or musculoskeletal disorders (MSDs). The purpose of this paper is mainly to investigate the changes when the RSI algorithm is used instead of the previous version of the Strain Index (both when the safe threshold limit is set at 3 and when it is set at 6), comparing the results with those provided by the ACGHIH(TLV) and the OCRA Index algorithm. Even though the RSI algorithm introduces important modifications compared to the previous 1995 version - among those the most important is the use of continuous rather than categorical multipliers that allow one to solve the problem of having, in some cases, a jump in terms of results when there is little variation of the parameters evaluated - marked differences still remain in the comparison with other methods, when looking for the maximum frequency allowed in the no-risk area in the hypothesis of a 1-minute cycle time and good posture.

In fact, except for in the comparison between RSI-SI(3)SI(6), the RSI provides similar results to the OCRA Index and ACGIH(TLV) in less than 1/3 of the overall combinations of force and duty cycle (including in the hypotheses that consider all results differing less than 0.3 efforts per second as equal, rather than approximating all frequencies less than 0.3 movements per second as zero).

What can be considered noteworthy, beyond the relative differences among the results, some of them normal when different algorithms are used, is that in some particular circumstances the methods seem to start from very different boundary conditions.

For example: in the hypothesis of a 1-minute cycle time, 8 hours of repetitive work and good posture:

the ACGIH(TLV) method allows 6 exertions per second in the net time of the cycle, while the RSI less than 1 (0.86), in the hypothesis of $\mathrm{BS}=1$ and $\mathrm{DC}=60 \%$;

- in the same conditions, but when $\mathrm{DC}=100 \%$, the ACGIH(TLV) method allows almost 2 exertions per second (1.7) while the RSI and the OCRA Index do 
not consider any frequency of movement as "safe" in this condition;

in the same conditions as above, but when $\mathrm{DC}=20 \%$ and $\mathrm{BS}=5$, the RSI method allows less than $0.5(0.31)$ exertions per second, while using the OCRA Index it is possible to stay in the "safe" area even if the number of exertions per second is over 4 (4.68).

In light of the above considerations, what clearly emerged is that a greater amount of epidemiological data would be desirable in order to better define the boundary conditions that can be considered harmful for a worker performing repeated movements.

Some limitations of this study must be considered: (i) only the raw application of the algorithms was applied, no modifications by an expert assessor were made on the results; (ii) some of the results obtained in the calculation are probably rarely found in the real field; (iii) only a few combinations of duty cycle (DC) and force (BS) are considered in order to obtain the maximum frequency in the no-risk area; (iv) only a 1-minute cycle time was considered; (v) in the study, a hypothesis of a good posture was always assumed

\section{REFERENCES}

[1] Harris-Adamson, C., Heisen, E.A., Kapellusch, J., Garg, A., Hegmann, K.T., Thiese, M.S., Dale, A.M., Evanoff, B., Burt, S., Bao, S., Silverstein, B., Merlino, L., Gerr, F., Rempel, D. (2015). Biomechanical risk factors for carpal tunnel syndrome: A pooled study of 2474 workers. Occupational and Environmental Medicine, 72(1): 33-41. https://doi.org/10.1136/oemed-2014-102378

[2] Gallagher, S., Heberger J.R. (2013). Examining the interaction of force and repetition on musculoskeletal disorder risk: A systematic literature review. Human Factors, 55(1): 108-124 https://doi.org/10.1177/0018720812449648

[3] Melchior, M., Roquelaure, Y., Evanoff, B., Chastang, J.F., Ha, C., Imbernon, E., Goldberg, M., Leclerc, A., the Pays de la Loire Study Group. (2006). Why are manual workers at high risk of upper limb disorders? The rule of physical work factors in a random sample of workers in France (the Pays De La Loire Study). Occupational and Environmental Medicine, 63(11): 754-761. https://doi.org/10.1136/oem.2005.025122

[4] Anita, A.R., Yazdani, A., Hayati, K.S., Adon, M.Y. (2014). Association between awkward posture and musculoskeletal disorders (MSD) among assembly line workers in an automotive industry. Malaysian Journal of Medicine and Health Sciences, 10(1): 23-28.

[5] Aublet-Cuvelier, A., Aptel, M., Weber, H. (2006). The dynamic course of musculoskeletal disorders in an assembly line factory. International Archives of Occupational and Environmental Health, 78(7): 578-584. https://doi.org/10.1007/s00420-006-0092-9

[6] Antonucci, A., Forcella, L., Bonfiglioli, R., Boscolo, P., Violante, F.S. (2016). Analytical characterization of movements in the spinal columns and risk assessment due to repeated movements of the upper limbs of building painters. International Journal of Occupational Safety and Ergonomics, 22(3): 340-349. https://doi.org/10.1080/10803548.2016.1155802

[7] Forcella, L., Bonfiglioli, R., Cutilli, P., Antonucci, A., Di Donato, A., Siciliano, E., Cortini, M., Violante, F.S.,
Boscolo, P. (2012). Occupational stress and biomechanical risk in a high fashion clothing company. Work, 41(1 2966-2970. https://doi.org/10.3233/WOR-2012-0550-2966

[8] Michaloski, A.O., Stradioto, J.P., de Paula Xavier, A.A. (2020). Ergonomics study in the productive process in civil construction in the external plastering activity. Advances in Intelligent Systems and Computing, 970: 245-255. https://doi.org/10.1007/978-3-030-20145-624

[9] Andersen, J.H., Kaergaard, A., Frost, P. (2002). Physical, psychosocial, and individual risk factors for neck/shoulder pain with pressure tenderness in the muscles among workers performing monotonous, repetitive work. Spine, 27(6): 660-667. https://doi.org/10.1097/00007632-200203150-00017

[10] Armstrong, T.J., Fine, L.J., Radwin, R.G., Silverstein, B.S. (1987). Ergonomics and the effects of vibration in hand-intensive work. Scandinavian Journal of Work, Environmental and Health, 13(4): 286-289. https://doi.org/10.5271/sjweh.2049

[11] Forcella, L., Bonfiglioli, R., Cutilli, P., Siciliano, E., Di Donato, A., Di Nicola, M., Antonucci, A., Di Giampaolo, L., Boscolo, P., Violante, F.S. (2011). Analysis of occupational stress in high fashion clothing factory with upper limb biomechanical overload. International Archives of Occupational and Environmental Health, 82(5): 527-535. https://doi.org/10.1007/s00420-0110702-z

[12] UNI ISO 11228-3. (2007). Ergonomics manual Handling. Part.3: Handling of Low Loads at Hight Frequency.

[13] Colombini, D., Occhipinti, E., Baracco, A. (2000). A new check-list model, set with the OCRA Index, to evaluate exposure to repetitive movements of the upper limbs. Proceedings of the XIV Triennial Congress of the International Ergonomics Association and 44th Annual Meeting of the Human Factors and Ergonomics Association, "Ergonomics for the New Millennium", pp. 716-719.

[14] ACGIH Worldwide. (2001). Hand Activity Level TLV. Cincinnati, $\mathrm{OH}$.

[15] Moore, J.S., Garg, A. (1995). The strain index: a proposed method to analyze jobs for risk of distal upper extremity disorders. American Industrial Hygiene Association Journal, 56(5): 443-458. http://dx.doi.org/10.1080/15428119591016863

[16] Bao, S., Howard, N., Spielholz, P., Silverstein, B. (2006). Quantifying repetitive hand activity for epidemiological research on musculoskeletal disorders - Part II: Comparison of different methods of measuring force level and repetitiveness. Ergonomics, 49(4): 381-392. https://doi.org/10.1080/00140130600555938

[17] Danuta, R.L. (2014). Comparison of concepts in easy-touse methods for MSD risk assessment. Applied Ergonomics, 45(3): 420-427. https://doi.org/10.1016/j.apergo.2013.05.010

[18] Rosecrance, J., Paulsen, R., Murgia, L. (2017). Risk assessment of cheese processing tasks using the Strain Index and OCRA Checklist. International. Journal of Industrial Ergonomics, 61: 142-148. https://doi.org/10.1016/j.ergon.2017.05.009

[19] Chiasson, M.T., Imbeau, D., Aubry, K., Delisle, A. (2012). Comparing the results of eight methods used to evaluate risk factors associated with musculoskeletal disorders. International. Journal of Industrial 
Ergonomics,

42(5):

$478-488$

http://dx.doi.org/10.1016/j.ergon.2012.07.003

[20] Serranheira, F., De Sousa Uva, A. (2008). Work-related upper limb musculoskeletal disorders risk assessment: different tools, different results! What are we measuring? Medicina y Seguridad del Trabajo, 54(212): 35-44. http://dx.doi.org/10.4321/S0465-546X2008000300004

[21] Sala, E., Torri, D., Tomasi, C., Apostoli, P. (2014). Risk assessment for upper extremity work related musculoskeletal disorders by applying six methods of ergonomic: An experience of ten years. Giornale Italiano di Medicina del Lavoro ed Ergonomia, 36(4): 260-266.

[22] Antonucci, A. (2019). Comparative analysis of three methods of risk assessment for repetitive movements of upper limbs: OCRA Index, ACGIH(TLV), and Strain Index. International Journal of Industrial Ergonomics, 70: 9-21. https://doi.org/10.1016/j.ergon.2018.12.005

[23] Garg, A., Moore, S., Kapellush, J.M. (2017). The Revised Strain Index: an improved model upper extremity exposure assessment model. Ergonomics, 60(7): 912-922. https://doi.org/10.1080/00140139.2016.1237678

[24] Garg A., Moore, S., Kapellush, J.M. (2007). The Strain Index to analyze jobs for risk of distal upper extremity disorders: Model validation. IEEE International Conference on Industrial Engineering and Engineering Management,

pp. 497-499. https://doi.org/10.1109/IEEM.2007.4419239

[25] Borg, G. (1990). Psychophysical scaling with applications in physical work and the perception of exertion. Scandinavian Journal of Work, Environmental and Health, 16(1): 55-58 https://doi.org/10.5271/sjweh.1815

[26] Radwin, R.G., Azari, D.P., Lindstrom, M.J., Ulin, S.S., Armstrong, T.J., Rempel, D. (2015). A frequency-duty cycle equation for the ACGIH hand activity level. Ergonomics, $58(2)$ : 173-183. http://dx.doi.org/10.1080/00140139.2014.966154

\section{NOMENCLATURE}

a Force multiplier: parameter that refers to the force applied (OCRA method)

ACGIH American Conference of Government Industrial Hygienist method

ATA Number of actual technical action carried out during a work shift (OCRA method)

b Posture multiplier: parameter that refers to the posture (OCRA method)

BS Borg Scale of force (1 to 10), according to $\mathrm{NPF}_{\mathrm{AL}}$

c Stereotype multiplier: parameter that refers to the high repetition of the same movement (OCRA method)

D Parameter referred to the duration of exertion (SI and RSI method)
$\mathrm{DC}$

$D E$

$\mathrm{DM}$

$\mathrm{E}$

EM Efforts per minute: parameter that refers to the frequency of movement (RSI method)

$F$

$F^{\prime}$

$\mathrm{H} \quad$ Number of hours worked in a day (RSI method)

HAL Hand Activity Level: combination of $f$ and DC (ACGIH method)

HM Parameter that refers to the duration of the task per day measured in hours (RSI method)

I

IM Parameter referred to the intensity of exertion (S and RSI method)

$\mathrm{NPF}_{\mathrm{AL}}$ Intensity of exertion: parameter that refers to the force (RSI method)

Normalized Peak Force: relative level of effort on a scale of 1 to 10 based on the \% of the maximum voluntary contraction

NTC Net time of the cycle: time in the cycle in which movements are performed

OCRA Occupational Repetitive Action method

$P \quad$ Parameter referred to the posture (SI method)

PM Postural multiplier: parameter that refers to the anatomical position of the hand/wrist (RSI method)

$R$

RSI $\quad$ Revised Strain Index method

RTA Number of reference technical actions (OCRA method)

SI Strain Index method

$T \quad$ Parameter referred to the total time of repetitive tasks during the shift (SI method)

WMSD Work Related Musculoskeletal Disorders 